\title{
CHITAL (AXIS AXIS ERXLEBEN, 1777) HERD COMPOSITION AND SEX RATIO ON THE NALLAMALA HILLS OF EASTERN GHATS, ANDHRA PRADESH, INDIA
}

\author{
C.Srinivasulu \\ Wildlife Biology Section, Department of Zoology, Osmania University, Hyderabad, Andhra Pradesh 500007, India. \\ Email: masawa@hd2.dot.net.in
}

\begin{abstract}
A total of 32 chital herds comprising 383 individuals with a maximum herd size of 12 were sighted in the Nallamala Hills. Sex ratio varied seasonally. More bucks associated with groups during winter. Chital on the Nallamala hills tends to be in smaller herds of two to five individuals (68\% of the total groups sighted), that were more common during summer and winter seasons. The apparent seasonal variation in the herd composition and sex ratio was due to behavioural modifications.
\end{abstract}

\section{Keywords}

Chital, Axis axis, herd composition, sex ratio, Nallamala Hills, Eastern Ghats, India

\section{Introduction}

Chital, Axis axis (Erxleben, 1777), is one of the most common and widely distributed cervids in the Indian subcontinent. The wild populations of this species are under stress due to anthropogenic activities in their habitats throughout their distribution in South Asia, resulting in many changes in their behavioural repertoire. One such change is in the herd size and composition, which is directly related to the availability of browse and cover. Numerous studies (Ables, 1977; Barrette, 1985, 1987; Berwick, 1974; Eisenberg \& Lockhart, 1972; Johnsingh, 1983; Krishnan, 1972; Mishra \& Wemmer, 1987; Mishra, 1982; Miura, 1981; Shankar Raman et al., 1996; Schaller, 1967; Sharatchandra \& Gadgil, 1975; Tak \& Lamba, 1984) have indicated that chital is sensitive to environmental changes. Till date no study has been carried out on widely dispersed and low density chital population on the Nallamala Hills and the present investigation aims at filling this lacuna.

\section{Study area}

Nestled in the central part of Eastern Ghats in Andhra Pradesh, the Nallamala Hill Range is located between $15^{\circ} 20^{\prime}-16^{\circ} 31^{\prime} \mathrm{N}$ and $78^{\circ} 30^{\prime}-80^{\circ} 10^{\prime} \mathrm{E}$ (Fig. 1). It is a group of low hill ranges that span an area of 7,640sq.km. The vegetation is of southern tropical dry deciduous and southern tropical moist deciduous forest types intermingled with scrub (Champion \& Seth, 1968). The present study was conducted on the right bank of the Nagarjunasagar Srisailam Tiger Reserve. Although, known for its floral diversity (Ellis, 1968; Rao, 1998), the Nallamala Hill Range is home for about 71 species of mammals and 240 and odd species of birds (Nagulu et al., 1998; Rao et al., 1997).

\section{Methods}

Predetermined transects of two-kilometer length in the forested tracts of Nallamala Hills were surveyed by walk or jeep from March 1996 to February 1998. When Chital herds were sighted, observations were made to determine their numbers in the herd and sex of each animal. The observations were ocular aided with 8 x 40 binoculars. Only those herds were considered where sex of all individuals could be ascertained.

\section{Results and Discussion}

A total of 184 transects were surveyed during the study period averaging a minimum of at least six per month. Altogether 32 Chital herds comprising 383 individuals were sighted. The herd size averaged 11.96 individuals per herd with least in summer season and peak during the winter $(\mathrm{P}<0.005)$. The mean herd size of Chital varied significantly $\left(\mathrm{F}_{2,31}=6.23, \mathrm{P}<0.001\right)$ and was $6.125 \pm 1.24$ during the summer, while, it was $14.75 \pm 4.02$ in monsoon and $27 \pm 4.07$ in winter (Fig. 2).

The sex ratio was found to be varying from month to month during the study period. It was recorded least in the months of August 1997, July 1996, February 1998 and September 1997 with 


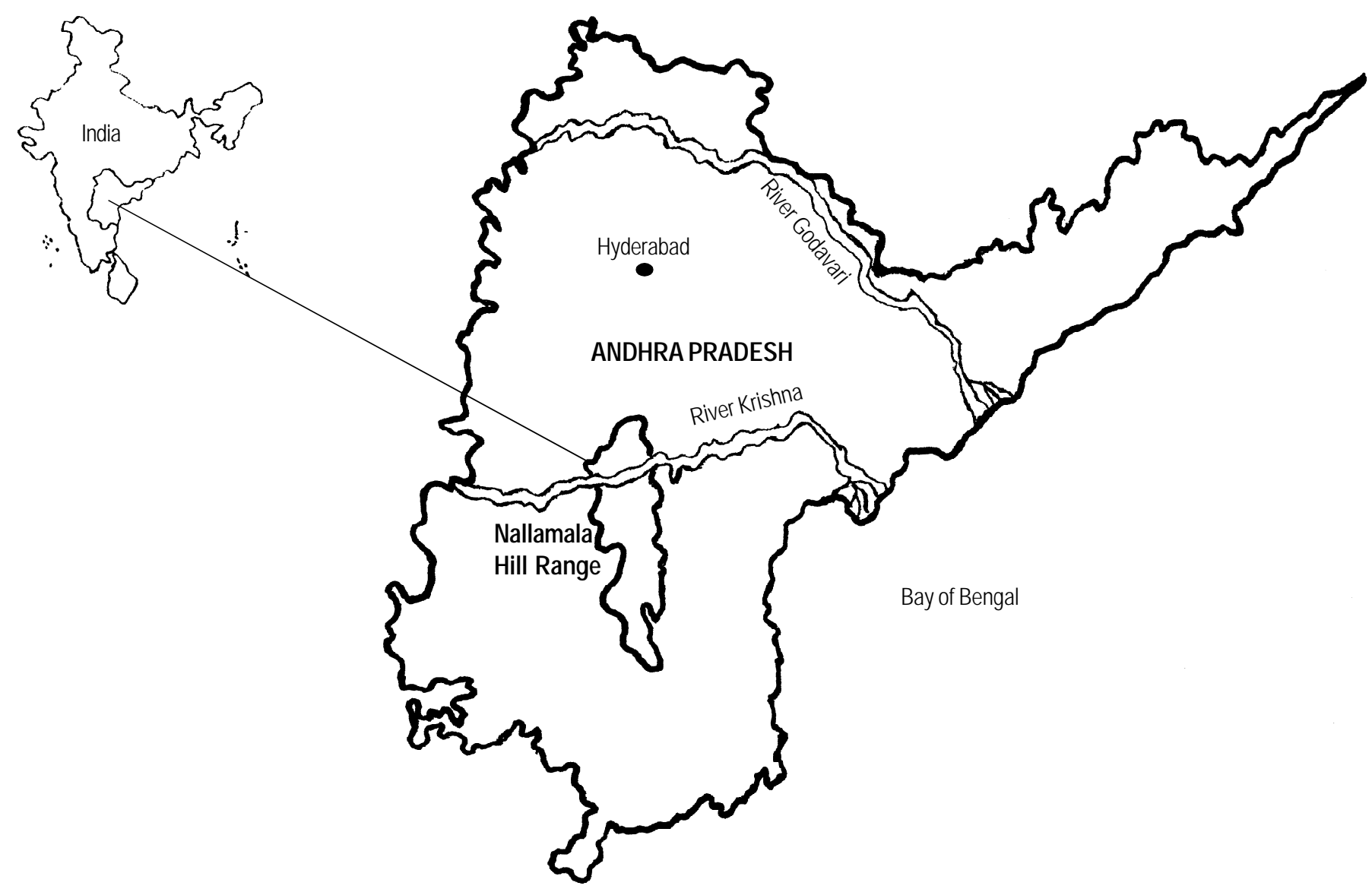

Figure 1. Map depicting the Nallamala Hill Range in Andhra Pradesh, India

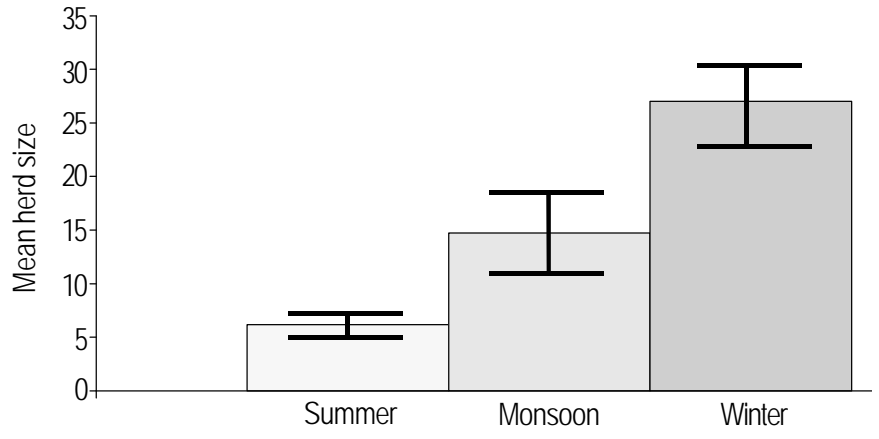

Figure 2. Seasonal variation in mean herd size of Chital on Nallamala hills an average of 27,33, 42 and 45 bucks per 100 does. While it was recorded highest during November 1996 and 1997, July 1996 and December 1997 with an average of 92, 83 and 75 (each for last two months), respectively. On an average the sex ratio was approximately 58 bucks per 100 does throughout the study period (Fig. 3).

Sex ratio varied from season to season and it was observed that more bucks tended to associate with groups during winters followed by summer and monsoon (Fig. 4). Khan and Vohra (1992) reported similar observation.

Of the total 383 individuals observed, 22 were fawns. Fawns were recorded almost throughout all the months of the year, though the number of fawns sighted peaked during late winter (almost half the fawns recorded). During the monsoon and summer the sighting percentage was 27 and 22 respectively.

The most common herd size during the study period was two to five individuals contributing about 68 per cent of the total herds sighted. Chital herds of this size were frequently sighted during 


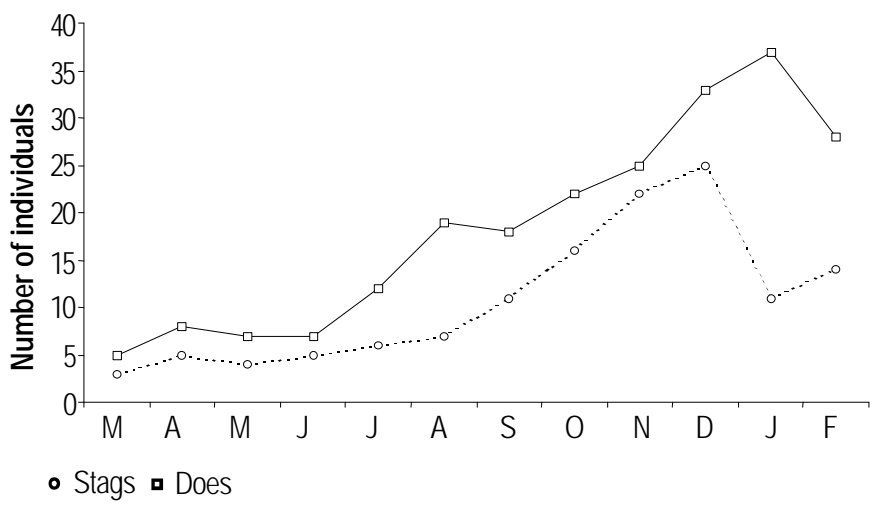

Figure 3. Monthly variation in sightings of stags and does of
Chital on Nallamala hills

the summer and winter seasons. Herd size increased from five and above during monsoon. The largest herd observed comprised 32 individuals. It was found that the Chital tended to form larger herds of 100-150 individuals during the monsoon months at preferred grazing grounds in Pecheruvu area of the Nagarjunasagar-Srisailam Tiger Reserve, one of the two protected areas on the Nallamala Hills. However, these large herds were not taken into consideration to summarize the group composition and sex ratio as it was felt that it might lead to severe discrepancy during the statistical analysis due to their extreme nature. Moreover, such large groups were sighted either on the glades along the Pecheruvu Tank or bedded in transitional zones in association with Sambar (Cervus unicolor). As been stated earlier, only chital herds that were encountered in forested tracts were considered for analysis to understand its herd composition and sex ratio.

The present study reveals that the Chital of Nallamala Hill Ranges are widely dispersed and tend to be in smaller herds of 2-5 individuals. The seasonal variation in herd size reflects changes in feeding and breeding behavior due to increased anthropogenic and biotic pressures as was also observed by Karanth and Sunquist (1992) in Nagarhole. Raman (1997) opined that Chital herds change in size temporally and in relation to habitat. Increase in herd size in relation to availability of food has been documented earlier by Schaller (1967), Sharatchandra and Gadgil (1975), Johnsingh (1983), and, Khan et al. (1985). The present study revealed the formation of large herds during the evenings when Chital conglomerate to feed in open grassland patches. Sex ratio varied seasonally that can be attributed to behavioural changes associated with reproduction. During the winter, especially January and February, the does tend to separate themselves from the groups to fawn. This is the period when more bucks are sighted than does. During the subsequent months, the group size swells up and so does the percentage

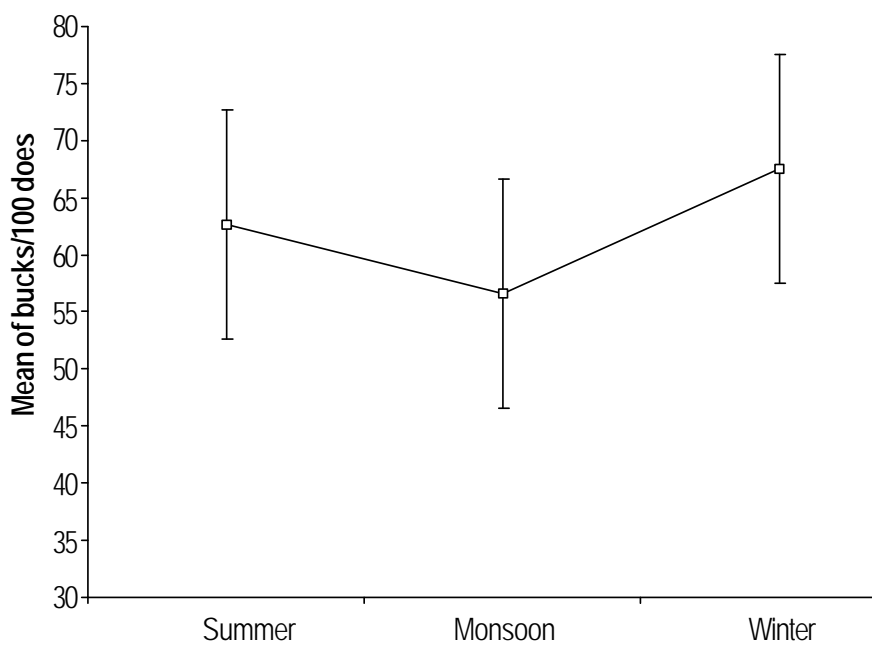

Figure 4. Seasonal variation in sex ratio of Chital on Nallamala hills

sighting of bucks associated with does. Such variations in herd size in relation to social behaviour, rutting behaviour and fawning observed earlier by Grafs and Nichols (1968), and, Fuchs (1977) indicates that conglomeration during rutting season facilitates social interaction and breeding opportunities.

Thus, it is evident that the apparent seasonal variation in herd composition and sex ratio of Chital on Nallamala Hills is due to the behavioral modifications in lieu with the availability of preferred palatable species and breeding activity.

\section{Acknowledgements}

I thank Prof. J.V. Ramana Rao and Dr. V. Nagulu for guidance, encouragement and stimulating discussions. I also thank the Head, Department of Zoology, Osmania University for permitting me to carry out the present study. Thanks are also due to Mr. T. Ramakrishna (Chief Wildlife Warden), Mr. A.V. Joseph (Conservator of Forests - Wildlife Management), Mr. D. Sudhakar (Project Director, Nagarjunasagar-Srisailam Tiger Reserve) for permitting me to carry out the present study. I thank Mr. K. Tulsi Rao (Asst. Director, Project Tiger) and Dr. V. Vasudeva Rao for discussions and help in the field. I acknowledge the financial assistance in the form of Senior Research Fellowship extended by CSIR, New Delhi. Ms. Bhargavi Srinivasulu and Mr. Harsha Reddy provided necessary comments.

\section{References}

Ables, E.D. (Editor) (1977). The Axis Deer in Texas. Caesar Kleberg Research Program and Texas A and M University, Texas.

Barrette, C. (1985). Antler eating and antler growth in wild Axis Deer. Mammalia 49: 491-501.

Barrette, C. (1987). Mating behaviour and mate choice by wild Axis Deer in Sri Lanka. Journal of the Bombay Natural History Society 
84(2): 361-371.

Berwick, S.H. (1974). The community of wild ruminants in the Gir Forest ecosystem, India. Ph.D. Dissertation, Yale University.

Champion, H.G. and S.K. Seth (1968). A Revised Survey of Forest Types of India. Manager of Publications, Government of India, New Delhi.

Eisenberg, J.F and M. Lockhart (1972). An ecological reconnaissance of Wilpattu National Park, Ceylon. Smithsonian Contribution to Zoology 101: 1-118.

Ellis, J.L. (1968). The flora of the Nallamalais on the Eastern Ghats of India - 1: A preliminary list. Bulletin of the Botanical Survey of India 10(2): 149-160.

Fuchs, E.R. (1997). Behaviour. In: Ables, E. D. (Editor) The Axis Deer in Texas. Caesar Kleberg, Research Program and Texas A and M University, Texas. pp. 24-52.

Grafs, W. and L. Nichols (1966). The Axis Deer in Hawaii. Journal of the Bombay Natural History Society 63: 629-734.

Johnsingh, A.J.T. (1983). Large mammalian prey-predators in Bandipur. Journal of the Bombay Natural History Society 80(1): 1-57. Karanth, K.U. and M.E. Sunquist (1992). Population structure, density and biomass of large herbivores in the tropical forests of Nagarhole, India. Journal of Tropical Ecology 8: 21-35.

Khan, J.A. and U. Vohra (1992). Group size and group composition of Chital (Axis axis) in Gir, Gujarat, India. Mammalia 56: 662-665

Khan, J.A., R. Chellam and A.J.T. Johnsingh (1995). Group size and age-sex composition of three major ungulate species in Gir Lion Sanctuary, Gujarat, India. Journal of the Bombay Natural History Society 92: 295-302.

Krishnan, M. (1972). An ecological survey of larger mammals of peninsular India. Journal of the Bombay Natural History Society 69(3): 469-501.

Mishra, H.R. (1982). The ecology and behaviour of Chital (Axis axis) in the Royal Chitwan National Park, Nepal. Ph.D. Thesis, University of Edinburgh, Edinburgh.
Mishra, H.R. and C. Wemmer (1987). The comparative breeding ecology of four cervids in Royal Chitwan National Park. In: Wemmer, C. (Editor) Biology and Management of the Cervidae. Smithsonian Institute Press, Washington, pp. 259-271.

Miura, S. (1981). Social behaviour of the Axis Deer during the dry season in Guindy Sanctuary, Madras. Journal of the Bombay Natural History Society 78(2): 125-138.

Nagulu, V., V.V. Rao and C. Srinivasulu (1998). Biodiversity of select habitats in Eastern Ghat regions of Andhra Pradesh. In: The Eastern Ghats. Proceedings of the National Seminar on the Conservation of Eastern Ghats, March 24-26, 1998, Visakhapatnam. EPTRI, Hyderabad \& Andhra University, Waltair, pp. 6-35.

Rao, R.K. (1998). Nallamalai Hills - among world centres of plant diversity. In: The Eastern Ghats. Proceedings of the National Seminar on the Conservation of Eastern Ghats, March 24-26, 1998, Vishakapatnam. EPTRI, Hyderabad and Andhra University, Waltair, pp. 317-321.

Raman, S.T.R. (1997). Factors influencing seasonal and monthly changes in the group size of Chital or Axis Deer in southern India. Journal of Bioscience 22(2): 203-218.

Raman, S.T.R., R.K.G. Menon and R. Sukumar (1996). Ecology and management of Chital and Blackbuck in Guindy National Park, Madras. Journal of the Bombay Natural History Society 93(2): 178192.

Rao, V.V., V. Nagulu, M. Anjaneyulu, B. Srinivasulu, C. Srinivasulu and J.V.R. Rao (1997). Status of avifauna of Rajiv Gandhi National Park, Andhra Pradesh, India. Pavo 35(1\&2): 85-100.

Schaller, G.B. (1967). The Deer and the Tiger. The University of Chicago Press, Chicago.

Sharatchandra, H.C. and M. Gadgil (1975). A year of Bandipur. Journal of the Bombay Natural History Society 72(4): 623-647.

Tak, P.C. and B.S. Lamba (1984). Ecology and ethology of the Spotted Deer Axis axis axis (Erxleben) (Artiodactyla: Cervidae). Record of the Zoology Survey of India Occassional Paper 43: 1-100. 